\section{TOOTH MORPHOLOGY AT YOUR FINGERTIPS}

A dental app called 'Real Tooth Morphology' has been released by two academics from the University of Sheffield.

The groundbreaking app uses high resolution micro-CT scan data of real teeth. The data have been collected and processed by the academics, who used 3D reconstruction techniques to allow the external and internal structures of the teeth to be explored in 3D in great detail.

Included in the app is a guide to the morphology and features of the teeth, with 3D demonstrations of how they relate to the tooth in question. A major advantage of using real teeth is that many show interesting and unusual features, which would be seen on dental patients. These can be explored and are explained through an interactive guide.

The app is the perfect tool for dental professionals, dental students and anyone else wishing to learn the medical structure of the teeth and mouth. The high detail and resolution available when viewing an individual tooth, including the internal structures, allows many interesting features of the teeth to be seen and understood.

The app contains an educational guide with facts and detail about each high resolution tooth. This has been written by published experts in the field and gives a medically correct overview of the morphology of the teeth. Real Tooth Morphology can replace a dental textbook as a learning tool and has the advantage of being able to demonstrate the points shown using real 3D tooth models rather than flat diagrams.

The app is available now on most touchscreen devices via the Apple App Store and android Google Play Store. A free trial

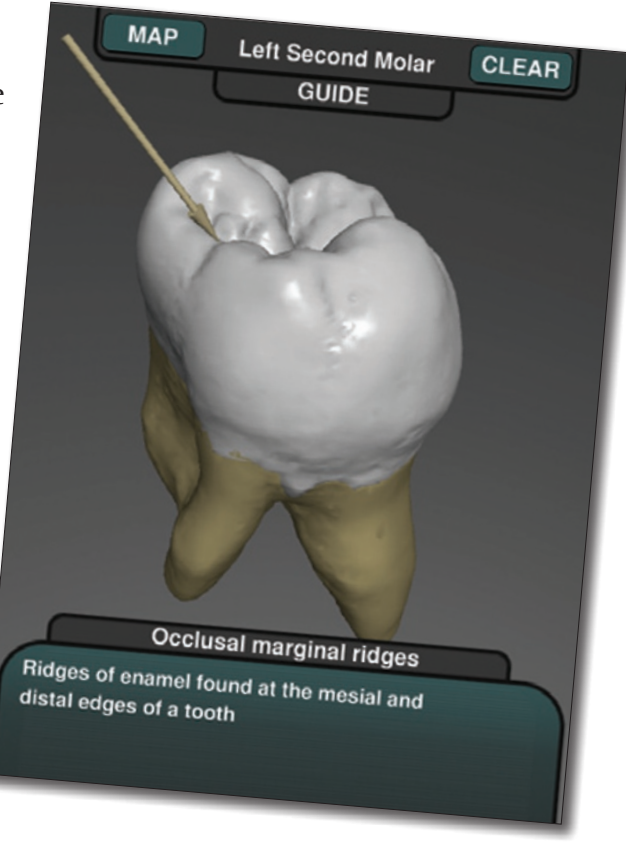

version of the app is available containing data on a single tooth. www.realtooth.co.uk

\title{
PROTECT AGAINST THE EFFECTS OF ACID WEAR
}

Many dental professionals are aware of acid wear - but new research conducted for Pronamel throws light on just how often this condition is seen in practice.

In a survey of 200 dental professionals, completed in January 2013, 83.5\% said that they saw acid wear amongst their patients on a weekly basis, and $86 \%$ felt that the condition was on the increase. Eighty-nine percent of dentists agreed that acid wear posed a significant threat to patients' oral health.

Patients are also aware of the problem: nearly $60 \%$ of dentists reported that an increasing number of patients were expressing concerns to them about acid wear. It's worth bearing in mind that patients are more and more likely to ask you for information on the condition - you can refresh your own knowledge at gsk-dentalprofessionals.co.uk.

Patients at risk of the effects of acid wear should be given dietary advice and educated on habits to avoid, like holding acidic drinks in the mouth for long periods. They can also be recommended a toothpaste, like Pronamel, specifically designed to protect against the effects of acid wear.

Pronamel toothpaste is proven to re-harden acid-softened enamel and build protection against future acid challenges. The unique low-abrasion, pH-neutral formula is optimised to deliver maximum fluoride to a patient's enamel.

www.gsk-dentalprofessionals.co.uk.

\section{ACID WEAR HEADLINING AT ORAL HEALTH CONFERENCE}

Dental teams planning a visit to the British Society of Dental Hygienists and Therapists' Oral Health Conference and Exhibition in November should ensure that they call at the GSK stand to find out more about Pronamel and Corsodyl.

Pronamel toothpaste is proven to re-harden acidsoftened enamel and provide protection from the effects of acid wear. Corsodyl is the number one dentist-recommended brand for gum problems.
GSK have also sponsored a lecture at the event: 'Under attack! Helping our patients improve their defences in the fight against acid wear'.

Visitors to the GSK stand will receive Pronamel and Corsodyl Daily sample boxes.

www.bsdht.org.uk

\section{WOW YOUR PATIENTS WITH SHARP TREATMENT IMAGERY}

Dental Consult Applications (DCA) is an incredible visual tool designed for use chairside to help dentists explain different dental treatments to their patients. Digital SLR photos of real patient cases, rather than models, demonstrate the sequential steps performed in each treatment.

The DCA app, originally launched in Canada with great success and now available internationally, is concisely categorised and includes images of dental implant cases, bridges, dentures, crowns, veneers, tooth whitening, and even basic treatments like restored decay. DCA documents treatments from start to finish and provides digital images of laboratory steps as well.

For more information see http://dentalconsultapplications.com or search on 'Dental Consult Applications' in the Apple App Store. 